DOI: http://dx.doi.org/10.1590/1981-7746-sol00185

\title{
O CUIDADO PARA PESSOAS COM HIV/AIDS SOB A ÓTICA DE AGENTES COMUNITÁRIOS DE SAÚDE
}

\section{CARE FOR PEOPLE WITH HIV/AIDS UNDER THE PERSPECTIVE OF COMMUNITY HEALTH WORKERS}

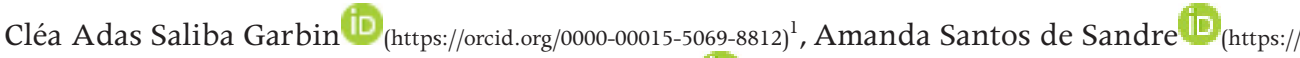
orcid.org/0000-0002-7884-4890) ${ }^{1}$, Tânia Adas Saliba Rovida (iD (https://orcid.org/0000-0003-1327-2913) ${ }^{1}$, Karina Tonini dos Santos Pacheco (iD (https://orcid.org/0000-0002-4687-6062) ${ }^{2}$, Antonio Carlos Pacheco Filho (iD) (https://orcid.org/0000-0002-5625-5884) ${ }^{1}$, Artênio José Ísper Garbin (htps://orcid.org/0000-0002-7017-8942) ${ }^{1}$
\end{abstract}

\footnotetext{
${ }^{1}$ Universidade Estadual Paulista Júlio de Mesquita Filho, Departamento de Odontologia Infantil e Social, Araçatuba, São Paulo, Brasil.

<cgarbin@foa.unesp.br>

${ }^{2}$ Universidade Federal do Espírito Santo, Centro Biomédico, Departamento de Medicina Social, Vitória, Espírito Santo, Brasil.
}

Resumo Este estudo buscou investigar a experiência de atuação dos agentes comunitários de saúde em relação aos indivíduos que vivem com HIV/Aids em áreas de risco social. Trata-se de uma pesquisa de natureza qualitativa, realizada no ano de 2015 com agentes comunitários atuantes em município de médio porte do estado de São Paulo, Brasil. A produção das narrativas foi realizada pelo método do grupo focal, interpretadas e analisadas por meio da análise temática de conteúdo. O preconceito apresentou-se como a principal causa das dificuldades de atuação dos agentes; porém, a criação do vínculo com os usuários, aliada à conquista da confiança, foi a principal potencialidade nas ações desses profissionais. Torna-se essencial o rompimento da barreira gerada pelo preconceito para uma efetiva atuação dos agentes comunitários de saúde nos territórios, para que possam colaborar com o acolhimento desses usuários e com a redução dos efeitos da vulnerabilidade existente. Palavras-chave Estratégia Saúde da Família; agentes comunitários de saúde; síndrome da imunodeficiência adquirida; acolhimento.
Abstract The present study had the goal of investigating the work experience of community health workers with individuals who live with HIV/Aids in areas of social risk. It is a qualitative research performed in 2015 with community health workers of medium-sized municipalities in the state of Paulo, Brazil. The narratives were produced using the focus group method, and they were interpreted and analyzed through the thematic analysis of content. Prejudice was the main cause of difficulties in the work of these professionals; however, the establishment of bonds with the users, coupled with the fact that the workers gained their trust, was the main potentiality in the actions of those professionals. Therefore, it is essential that we break the barrier generated by prejudice in order to guarantee and effective work in the territories on the part of the community health workers, so they can contribute to the embracement of these users and to the reduction in the effects of the existing vulnerability.

Keywords family health strategy; community health workers; acquired immunodeficiency syndrome; user embracement. 


\section{Introdução}

As mudanças nos padrões epidêmicos e a ampliação do conceito de saúde possibilitaram a criação de políticas de prevenção da infecção pelo HIV ao longo dos anos, e um dos desafios enfrentados por essas políticas relaciona-se à descentralização das ações de atenção e prevenção do HIV/Aids, atualmente uma das metas globais da Organização Mundial da Saúde (França, 2009; WHO, 2017).

No processo de descentralização, a atenção primária à saúde passou a ter papel fundamental na redução da vulnerabilidade ao HIV/Aids, com atuação em âmbito individual e coletivo, e atribuiu-se à Estratégia Saúde da Família (ESF) responsabilidade nas ações voltadas para o HIV (Silva e Cardoso, 2008). Dentro da equipe da ESF, os agentes comunitários de saúde (ACSs) desempenham papel fundamental na integralidade da assistência à saúde em razão do seu campo de atuação, que favorece o contato direto com o usuário do sistema de saúde (Ribeiro et al., 2010).

Algumas diretrizes foram formuladas pelo Ministério da Saúde para a atuação do ACS na prevenção de HIV/Aids, na disseminação de informações, na realização de encaminhamentos e na avaliação de serviços para atendimento (Brasil, 2001). As referidas diretrizes podem contribuir para o diagnóstico precoce da infecção, para a prevenção de novos casos e para a promoção do processo de referência e contrarreferência do sistema de saúde(Brasil, 2001; Holmes et al., 2014; Wood et al., 2014; Chaiyachati et al., 2014; Anglemyer et al., 2014).

Este estudo buscou investigar a experiência de atuação dos ACSs em relação aos indivíduos que vivem com HIV/Aids em áreas de risco social, e discutir como esses atores, considerados peças-chave para a ESF, podem colaborar para o cuidado integral do usuário em questão.

\section{Metodologia}

Trata-se de um estudo de natureza qualitativa, realizado em maio de 2015 com os ACSs atuantes em três unidades de Saúde da Família (USFs), localizadas em áreas de risco social em zona urbana de um município de médio porte do interior do estado de São Paulo, Brasil, cujos índices de violência se mostraram maiores que os da capital do estado, município com taxa de, aproximadamente, 20 homicídios por 100.000 habitantes (Waiselfiz, 2012). A taxa de detecção, por 100.000 habitantes, de casos de Aids notificados no município, em 2015, foi de 19,7. A razão de sexo e o coeficiente de mortalidade no mesmo ano foram de 1,5 e 12,5, respectivamente (Brasil, 2018).

Cada USF continha uma equipe de Saúde da Família completa. Todos os 29 agentes atuantes nas áreas de risco social participaram do estudo, exceto 
um, que se encontrava em afastamento médico. A idade dos profissionais variou entre 25 e 45 anos, cinco eram do sexo masculino e 24 do sexo feminino e todos trabalhavam na sua respectiva USF havia mais de um ano. Os profissionais foram contatados pessoalmente, no local de trabalho, onde foi agendado o melhor horário e local comum para a realização das reuniões do grupo focal (GF).

Como relatado anteriormente, a produção dos dados foi realizada pelo método do GF, adequado à captação de experiências e atitudes, além de influências de aspectos socioculturais (Ressel et al., 2008). O GF permite a geração da discussão em grupo, por meio dos consensos e dissensos, o que não acontece nas entrevistas individuais. Foram realizadas cinco reuniões, quatro com seis participantes e uma com cinco participantes, no próprio ambiente das USFs.

O grupo foi conduzido por um moderador, que propôs o tema de discussão para os participantes, de acordo com um roteiro preparado com base nos objetivos do estudo, que incluía as seguintes questões centrais: ações voltadas ao cuidado de pessoas com HIV realizadas e como são desenvolvidas; ciência dos casos de usuários com este problema no território; percepção sobre a atuação dos ACSs em relação ao problema. Ficou a cargo do moderador encorajar os participantes a expressarem livremente seus sentimentos e opiniões sobre a questão em estudo, a compartilharem experiências, assim como manter a discussão focalizada, fazendo resumos e retomando o assunto quando algum desvio se pronunciava. As reuniões foram gravadas em áudio e posteriormente transcritas de forma integral. A duração média dos GFs foi de 45 minutos. Após realização de todos os grupos, a equipe de pesquisadores reuniu-se para discutir as impressões e realizar uma pré-análise do que foi discutido.

A técnica escolhida para análise das informações coletadas foi a análise de conteúdo temática proposta por Bardin (2009). Essa análise organiza-se em torno de três eixos: a pré-análise, a exploração do material e o tratamento dos resultados, com a inferência e a interpretação. Durante a pré-análise, as narrativas foram transcritas e organizadas em arquivos particulares. Realizou-se um contato inicial, por meio de uma leitura detalhada, que tornou possível uma visão do material no âmbito geral e nas suas peculiaridades, e serviu como base para a interpretação, segundo os objetivos da pesquisa. Na exploração do material, por sua vez, os trechos das narrativas foram selecionados e categorizados em núcleos temáticos, o que possibilitou a identificação e a problematização das ideias, explícitas e implícitas, e avultou os sentidos de forma a dialogarem com informações de outros estudos e do referencial teórico usado para este estudo. Por fim, na etapa do tratamento dos resultados, a síntese interpretativa foi o ponto de partida da articulação entre os objetivos do estudo, as inferências realizadas, a base teórica adotada e os dados empíricos. 
Esta pesquisa, que não contou com auxílio financeiro e não resulta de dissertação ou tese, foi avaliada e aprovada em seus critérios éticos (CAAE n. 44071115.0.0000.5420) pelo Comitê de Ética em Pesquisa da Faculdade de Odontologia de Araçatuba da Universidade Estadua Paulista (FOA/Unesp). Todos os participantes assinaram o termo de consentimento livre e esclarecido.

A análise das narrativas permitiu identificar os seguintes núcleos temáticos: 'Omissão, estigma e preconceito' e 'Realidade versus expectativas de atuação'.

\section{Omissão, estigma e preconceito}

Quando discutida a atuação dos ACSs diante dos pacientes HIV positivos, a omissão por parte dos pacientes foi relatada como fato muito comum em todos os GFs. Os profissionais relataram que muitos fogem do contato com eles, poucos se abrem e contam com a ajuda oferecida:

Porque quando a gente vai fazer o cadastro da família e lá tem a pergunta, eles vão lá e negam.

Ele faz tratamento em São Paulo. (...) Porque eu acho que, na minha opinião, eu acho que se ele faz o tratamento aqui, ele acha que vai esparramar, né?

Na minha área eu tenho, e ele tinha tanto receio que ele me via e se escondia, fechava as portas. Mas eu fui bem persistente, até que hoje eu entro na casa dele, tomo café com ele. E ele conta toda a vida dele pra mim. Então é uma coisa só nossa, uma coisa minha e dele.

Uma pessoa que descobre viver com HIV pode se sentir envergonhada e marginalizada por pensar que irão associá-la a imagens sociais carregadas negativamente e discriminá-la. Como resultado, pode decorrer uma série de comportamentos e sentimentos, entre os quais respostas antecipatórias e defensivas, dificuldade de aceitação do diagnóstico e reações de retraimento (Zambenedetti e Both, 2013).

Observou-se, no relato dos entrevistados, que alguns pacientes preferem realizar o tratamento em serviços distantes de onde residem, com receio de serem identificados ao entrarem no serviço ou por não confiarem na capacidade das equipes de garantir o sigilo.

Conforme relatado em todos os GFs, os ACSs sabem dos casos de HIV por meio do relato de terceiros, vizinhos ou parentes e por meio de documentos, como o prontuário do paciente. 
Tem uma que não abriu o jogo até hoje (...) E a outra eu fiquei sabendo através de exames que está na pasta dela.

A presença de um estigma que depende da revelação diagnóstica, como é o caso da infecção pelo HIV e a Aids, muitas vezes é permeada por uma dinâmica de segredo, revelação ou encobrimento. Os relatos dos agentes auxiliam a compreender as posições por eles ocupadas em tal dinâmica, na qual participam do processo de gestão e controle da informação. Um importante fator nessa dinâmica diz respeito ao modo pelo qual o profissional teve acesso ao diagnóstico: pelo próprio usuário; por outro profissional da equipe ou prontuário; por outras pessoas do território atendido. A literatura não apresenta um consenso sobre se o ACS deve ou não ter acesso ao diagnóstico do paciente. Esta, porém, é a principal dificuldade relatada por eles na sua atuação ao atender o portador de HIV (Lelis et al., 2012; Zambenedetti e Both, 2013), o que sugere que os ACSs entendem sua atuação voltada para esta população com base em uma matriz predominantemente focada no indivíduo acometido, o que não significa desconsiderar questões coletivas populacionais.

Não! Não é problema! A gente não trata. A gente não controla! (...) Então pra nós, infelizmente... Infelizmente... Não é problema, nem preocupação.

O preconceito por parte da comunidade, dos agentes e dos próprios pacientes foi um assunto bastante discutido nos GFs.

... Quando eu fiquei sabendo que ele era, então as vizinhas falavam "O quê? Você vai passar ali?", "É o aidético", isso me machucava, eu nem respondia.

Eu me sinto totalmente constrangido de ter que ir no postão, muitas vezes (...) E todo mundo que passa por aquele corredor, quando você olha de longe, é prejulgado.

Existe sim, né?! Às vezes até do próprio paciente. Eu fui fazer o cadastro e nas perguntas que tem lá, ele falou que não tinha nada daquilo, depois a mãe dele foi lá e disse: "ele é soropositivo!".

A Aids ainda é reconhecida socialmente como uma 'epidemia da imoralidade', já que inicialmente estava associada a pessoas e comportamentos considerados desviantes. 'Epidemia da imoralidade' é um conceito desenvolvido por Guilhem sobre a percepção social do HIV/Aids vinculada a metáforas tais como 'peste gay' e às pessoas inicialmente acometidas pela doença, tais como prostitutas e usuários de drogas. Nesse sentido, a história moral da Aids permitiu a construção estigmatizada de que seria uma 'doença estrangeira', 
dos 'outros', daqueles considerados moralmente distantes, o que permite 'carimbar' as pessoas infectadas e, consequentemente, enraizar o preconceito na cultura da população (Pereira e Nichiata, 2011).

O preconceito é um fator impactante na atuação dos ACSs, pois, com medo do estigma, os indivíduos portadores do vírus acabam guardando segredo sobre o seu estado de saúde, o que compromete as ações de acolhimento e abordagem. Com isso, ganha relevo o fato de o ACS pertencer àquela comunidade e não raro conviver com a pessoa portadora do vírus em outros cenários sociais. O profissional que também é morador do território pode ter dúvidas e apreensões em relação ao sigilo das informações com as quais lida. Dessa forma, a informação e a educação exercem importante impacto na redução do estigma, e por isso constituem uma estratégia importante na redução de comportamentos discriminatórios (Zambenedetti e Silva, 2015).

O preconceito por parte dos próprios ACSs também aparece em um estudo realizado por Castanha e Araújo (2006). Esses autores sugerem a necessidade de uma abordagem psicossocial com os referidos profissionais, com a finalidade de reduzir o preconceito e a estigmatização em relação às pessoas que vivem com HIV/Aids. Ressaltam ainda que o medo, o desconhecimento e as questões religiosas ou morais (relacionadas à via de contaminação) podem ser barreiras para a atuação do ACS e comprometer sua a prática educativa no território.

\section{Expectativas versus Realidade de atuação}

As atividades realizadas no âmbito da APS, na USF onde os ACSs atuam, são o teste rápido, a disponibilização de preservativos e a promoção de campanhas específicas, embora essas ocorram com pouca frequência, conforme exposto:

Que nem agora, que foi implantado no mês de dezembro, só pra isso, pro DST/ Aids (...) A campanha é o "dezembro vermelho", que as pessoas podem vir, fazer o teste rápido na UBS [Unidade Básica de Saúde]. Então começou esse ano (...) Mas ainda existe o teste rápido na unidade, se a pessoa quiser fazer, ele é atendido pra fazer o teste rápido...

As diretrizes do Ministério da Saúde para a atuação dos ACSs recomendam um conjunto de ações que visam à conscientização, à prevenção e ao diagnóstico precoce da doença. São elas: perguntar às pessoas sexualmente ativas o que elas sabem sobre doenças sexualmente transmissíveis (DSTs) e fornecer informações adicionais; identificar e encaminhar pessoas que apresentam sinais ou sintomas dessas doenças; conscientizar sobre o uso da camisinha em todas as relações sexuais; falar sobre a importância do tratamento do parceiro sexual; informar que nem sempre as pessoas com DSTs apresentam 
sinais e sintomas; verificar se as pessoas encaminhadas às unidades de saúde realmente procuraram atendimento e se foram atendidas, medicadas e orientadas adequadamente (Brasil, 2001).

Porém, foi observado que na prática dos ACSs em muitos casos essas atividades não são realizadas e que, muitas vezes, esses agentes atuam de maneira informal entre a população. De acordo com alguns relatos, não há recomendações específicas para a atuação deles em relação à atenção e prevenção do HIV, o que, às vezes, os exime dessa responsabilidade.

Nós até temos um mapa nosso, mas a gente não acompanha isso. Soropositivo a gente não acompanha, aidético não acompanhamos (...).

Uma forma de mudar esse cenário seria a presença de profissionais da equipe de matriciamento para auxiliar na organização das primeiras ações dentro da UBS, e assim potencializar a descentralização, juntamente com o processo formativo. O conselheiro local de saúde também pode ser outra ferramenta importante para estimular ações específicas, devido ao seu conhecimento do território e à sua capacidade de produzir mobilização (Zambenedetti e Silva, 2016).

Apesar de a atuação ser revelada como informal, percebeu-se que os ACSs são capazes de identificar os diferentes níveis de vulnerabilidade em suas áreas de atuação. Isso é possível porque eles vivenciam o dia a dia das famílias, identificando os problemas sociais e os específicos de saúde. Essa percepção constitui um passo importante no agir em direção à prevenção e detetecção precoce da doença em questão, já que esse ator é um elemento-chave da ESF, que atua como elo entre a comunidade e a UBS (Garcia et al., 2017).

Nesta pesquisa, de acordo com os ACSs, uma boa atuação na atenção em relação ao HIV consiste em mais campanhas que visem à conscientização das pessoas, melhor acolhimento do paciente, além da própria capacitação sobre o assunto:

Acho que a boa atuação, melhor atuação é não ter preconceito... Tinha que ter mais estímulo.

Ter mais divulgação na mídia, até pra gente também, né? Palestras no bairro... pro nosso cotidiano aqui do Alvorada, né? Porque tem bem pouca divulgação, né? Orientação tem pouca mesmo.

No sentido da saúde, eu acho que a gente é responsável, pelo menos pela prevenção. Porque a gente está todo dia lá na nossa área, né? A gente pode chegar junto da pessoa e ter uma orientação só...

Dar um bom acolhimento à pessoa, sem discriminação... 
Zambenedetti e Silva (2015) indicam que a atenção primária se coloca efetivamente como território para o acesso ao diagnóstico de HIV e defendem a necessidade da qualificação das práticas profissionais, pautadas pelo respeito à diversidade, pelo direito à preservação da intimidade e ao sigilo das informações, além do respeito aos direitos humanos.

Investir na formação técnica e na valorização desses trabalhadores é sinônimo de fortalecimento da ESF. A educação permanente se faz necessária para superar gradativamente as lacunas das capacitações ofertadas aos ACSs. Queiroz, Silva e Oliveira (2014) propõem um modelo ancorado na Educação Popular em Saúde, que, em seus estudos, mostrou-se uma estratégia políticopedagógica possível e em conformidade com os objetivos propostos no âmbito da Política de Educação Permanente. De acordo com essas autoras, a Educação Popular em Saúde propicia condições objetivas de aprendizado significativo, baseado em discussões coletivas e processos reflexivos em torno de situações concretas que emergem no cotidiano de trabalho.

Outro ponto relevante é o papel que a Educação em Saúde pode assumir na atuação dos ACSs, os quais a consideram importante para o estabelecimento de estratégias em seus territórios de atuação. Nesse contexto, a educação, compartilhada entre os agentes e as pessoas soropositivas para o HIV, pode contribuir para diminuir os sofrimentos, para estreitar e humanizar as relações, para produzir uma atenção integral, para garantir o acesso aos serviços de saúde e para operacionalizar medidas de prevenção e de reabilitação com fornecimento de insumos (preservativos e antirretrovirais) (Holmes et al., 2014).

Duas dificuldades mais relatadas pelos ACSs na prevenção ou no acompanhamento de pacientes HIV foram a abordagem de pessoas com comportamento de risco ou vulneráveis, pois acham difícil lidar com a questão comportamental das pessoas; e o sigilo por parte dos enfermeiros e dos pacientes, que costumam esconder do agente o diagnóstico da doença, o que inviabiliza a efetividade de sua ação no cuidado.

(...) porque todo mundo fala que nós somos o elo da família... Nós somos o elo pra tudo... Então a gente deveria saber, né? Só que aí eles ficam com medo... Tem aquelas que guardam segredo e tem aquelas que não guardam... Isso aí é um sigilo que a pessoa tem que ter... é uma ética que a pessoa tem que ter... Então o correto era passar pra gente saber: "Paciente tal tem", pra gente pelo menos ter essa segurança, saber se a pessoa está tomando a medicação mesmo, se ela está tomando o coquetel correto.

É preciso refletir sobre a dupla posição de enunciação que os ACSs ocupam nesse processo, ora como homens e mulheres que vivem na comunidade, ora como profissionais da saúde(Oliveira et al., 2004). A duplicidade enunciativa 
assumida pelo ACSs pode ser interpretada de forma paradoxal pelo restante da equipe e pelos usuários do sistema de saúde, colocando em dúvida a posição por eles assumida a partir da revelação de um diagnóstico permeado por estigmas, como no caso do HIV (Oliveira et al., 2004; Zambenedetti e Both, 2013; Richey et al., 2014).

Outra dificuldade revelada foi a falta de infraestrutura física nas unidades de saúde em que atuam para a realização das atividades relativas ao HIV/Aids:

O nosso posto mesmo não é apropriado. Porque não tem uma sala específica pra isso [ações educativas].

A falta de estrutura física se dá, na maioria das vezes, devido à inexistência ou à inadequação do espaço das USFs, que funcionam em casas alugadas adaptadas para tal finalidade. Entretanto, a identificação de espaços sociais localizados no território para a realização de ações de educação em saúde pode ser uma alternativa viável quando o espaço físico da unidade se torna um empecilho para a realização dessas atividades.

Não é incomum as pesquisas que tratam da avaliação de serviços públicos de saúde evidenciarem a questão da infraestrutura como um dos problemas enfrentados no cotidiano de atuação das equipes, como é o caso de estudo realizado também em município paulista para avaliar o funcionamento da rede de atenção básica. Os profissionais atuantes tanto em UBS quanto em USF apontaram, entre outras, as seguintes questões relacionadas à infraestrutura: falta estrutura física para atender à demanda; necessidade de mais equipamentos de informática; carência de material de urgência (Cesar et al., 2014).

Apesar dessas dificuldades, relatou-se também uma grande potencialidade: a conquista de confiança dos pacientes, que, nesses casos, recebem o apoio emocional e físico dos agentes envolvidos:

... A gente também muitas vezes leva (camisinha) na bolsa, porque os pacientes pedem...

A gente às vezes faz igual a um psicólogo, fica escutando...

Se a gente puder pelo menos levar, ser um elo entre eles e o posto de saúde, mas também levar uma palavra amiga, porque geralmente a pessoa está com a autoestima baixa. (...) por isso que vem a depressão e a pessoa fica mais doente ainda... Ela pode vir a óbito bem mais rápido, né?

A criação do vínculo com o paciente é a principal potencialidade do ACS em sua atuação. Apesar dos desafios enfrentados, quando os ACSs conseguem romper as barreiras do preconceito e do medo dos pacientes, tornam- 
se instrumentos importantes para a promoção de saúde do indivíduo, pois ao oferecerem suporte físico e até emocional contribuem para a qualidade de vida do portador do vírus (Zambenedetti e Both, 2013; Lounsbury et al., 2015). Uma pesquisa qualitativa com pacientes HIV positivo ressaltou a importância do apoio social e do acesso ao suporte de profissionais da saúde no processo de adesão ao tratamento e sua continuação (Loggerenberg et al., 2015). O trabalho do ACS permite o fortalecimento do vínculo com a família, proporciona a aproximação das ações de saúde ao contexto domiciliar e aumenta a capacidade da população de enfrentar os problemas (Santos et al., 2011; Guimarães et al., 2017).

\section{Considerações finais}

A atuação dos ACS relacionada aos indivíduos que vivem com HIV/Aids, neste estudo, mostrou-se incipiente e informal. Entretanto, esses trabalhadores conhecem a importância do seu papel para uma boa atenção a esses usuários. Como uma das principais dificuldades indicaram o preconceito, que interfere significativamente em suas ações. Por sua vez, a principal potencialidade, quando a barreira do preconceito é quebrada, é a criação do vínculo com o usuário, que contribui de modo expressivo para a qualidade de vida do portador do vírus. Ademais, considera-se a necessidade do investimento no preparo desses profissionais, para que possam atuar de forma organizada e planejada na conscientização e na prevenção e no diagnóstico precoce da doença em voga. 


\section{Colaboradores}

Cléa Adas Saliba Garbin, Artênio José Ísper Garbin e Tânia Adas Saliba Rovida contribuíram com a concepção e delineamento do estudo, participaram da análise e interpretação dos resultados e da revisão crítica do conteúdo do artigo. Amanda Santos de Sandre coletou os dados, participou da interpretação e análise dos resultados e da redação do artigo. Karina Tonini dos Santos Pacheco e Antonio Carlos Pacheco Filho participaram da interpretação dos dados, da redação do manuscrito e da revisão crítica do conteúdo do artigo. Os autores declaram que não há conflitos de interesse.

\section{EL CUIDADO PARA PERSONAS CON HIV/SIDA BAJO LA ÓPTICA DE AGENTES COMUNITARIOS DE SALUD}

Resumen Este estudio buscó investigar la experiencia de trabajo de los agentes comunitarios de salud en relación a los individuos que viven con HIV/Sida en áreas de riesgo social. Se trata de una investigación de naturaleza cualitativa realizada en el año 2015 con agentes comunitarios de un municipio de tamaño mediano del estado de São Paulo, Brasil. La obtención de las narraciones se realizó a través del método del grupo focal, ¿interpretadas y analizadas por medio del análisis temático de contenido?. El preconcepto se presentó como la principal causa de las dificultades de trabajo de los agentes; sin embargo, la creación de un vínculo con los usuarios combinado a la conquista de la confianza fueron las principales potencialidades en las acciones de estos profesionales. Se vuelve esencial la ruptura de la barrera generada por el preconcepto para un trabajo efectivo de los agentes comunitarios de salud en los territorios, para que puedan colaborar con la acogida de estos usuarios y la reducción de los efectos de la vulnerabilidad existente.

Palavras clave Estrategia Salud de la Familia; agentes comunitarios de salud; síndrome de inmunodeficiencia adquirida; acogida. 


\section{Referências}

ANGLEMYER, Andrew et al. Early initiation of antiretroviral therapy in HIV-infected adults and adolescents: a systematic review. AIDS, London, v. 28, suppl, p. 105-118, 2014.

BARDIN, Laurence. Análise de conteúdo. Lisboa: Edições 70, 2009.

BRASIL. Ministério da Saúde. Informes da atenção básica. Brasília: Ministério da Saúde, 2001.

BRASIL. Ministério da Saúde. Departamento de Vigilância, Prevenção e Controle das IST, do HIV e das Hepatites Virais. Indicadores. 2018. Disponível em: <http://www.aids.gov. br/pt-br/gestores/painel-de-indicadoresepidemiologicos >. Acesso em: 26 jun. 2018.

CASTANHA, Alessandra R.; ARAÚJO, Ludgleydson F. Representações sociais de agentes comunitários de saúde acerca da Aids. Psicologia: Teoria e Prática, São Paulo, v. 8 , n. 1, p. 17-30, 2006.

CESAR, Marcelo C. et al. Avaliação da atenção primária no município de Piracicaba, SP, Brasil. Saúde em Debate, Rio de Janeiro, v. 38, n. esp., p. 96-306, 2014.

CHAIYACHATI, Krisda H. et al. Interventions to improve adherence to antiretroviral therapy: a rapid systematic review. AIDS, Londres, v. 28, suppl, p. 187-204, 2014.

FRANÇA, Martha S. J. Ciência em tempos de Aids: uma análise da resposta pioneira de São Paulo à epidemia. Interface: Comunicação, Saúde, Educação, Botucatu, v. 13, n. 28, p. 245-246, 2009.

GARCIA, Ana C. P. et al. Agente comunitário de saúde no Espírito Santo: do perfil às atividades desenvolvidas. Trabalho, Educação e Saúde, Rio de Janeiro, v. 15, n. 1, p. 283-300, 2017.

GUIMARÃES, Maria S. A. et al. Estratégia Saúde da Família e uso racional de medicamentos: o trabalho dos Agentes Comunitários em Palmas (TO). Trabalho, Educação e Saúde, Rio de Janeiro, v. 15, n. 1, p. 183-203, 2017.

HOLMES, Charles et al. Health systems implications of the 2013 WHO consolidated antiretroviral guidelines and strategies for successful implementation. AIDS, Londres, v. 28, suppl., p. 231-239, 2014.

LELIS, Ricardo T. et al. Vivendo com HIV/ AIDS: estudo da ocorrência de discriminação nos serviços de saúde. Revista Brasileira de Pesquisa em Saúde, Vitória, v. 14, n. 4, p. 22-28, 2012.

LOGGERENBERG, Francois et al. Qualitative study of patient motivation to adhere to combination Antiretroviral Therapy in South Africa. Aids Patient Care and STDS, Larchmont, v. 29, n. 5, p. 299-306, 2015.

LOUNSBURY, David W. et al. Simulating patterns of patient engagement, treatment adherence, and viral suppression: a system dynamics approach to evaluating HIV care management. Aids Patient Care and STDS, Larchmont, v. 29, suppl. 1, p. 55-63, 2015.

OLIVEIRA, Dora L. L. C. et al. A negociação do sexo seguro na TV: discursos de gênero nas falas de agentes comunitárias de saúde do Programa Saúde da Família de Porto Alegre, Rio Grande do Sul, Brasil. Cadernos de Saúde Pública, Rio de Janeiro, v. 20, n. 5, p. 1.309-1.318, 2004.

PEREIRA, Adriana J.; NICHIATA, Lucia Y. I. A sociedade civil contra a Aids: demandas coletivas e políticas públicas. Ciência \& Saúde Coletiva, Rio de Janeiro, v. 16, n. 7, p. 3.249-3.257, 2011.

QUEIROZ, Danielly M.; SILVA, Maria R. F.; OLIVEIRA, Lúcia C. Educação permanente com agentes comunitários de saúde: potencialidades de uma formação norteada pelo referencial da Educação Popular e Saúde. Interface: Comunicação, Saúde, Educação, Botucatu, v. 18, supl. 2, p. 1.199-1.210, 2014. 
RESSEL, Lucia B. et al. O uso do grupo focal em pesquisa qualitativa. Texto Contexto Enfermagem, Florianópolis, v. 17, n. 4, p. 779-786, 2008.

RIBEIRO, Paula M. et al. Profiles of Female Vulnerability to HIV/AIDS in Belo Horizonte and Recife: a comparison of white and black/ mixed women. Saúde e Sociedade, São Paulo, v. 19, n. 2, p. 21-35, 2010.

RICHEY, Lauren E. et al. From diagnosis to engagement in hiv care: assessment and predictors of linkage and retention in care among patients diagnosed by emergency department based testing in an Urban Public Hospital. Aids Patient Care and STDS, Larchmont, v. 28, n. 6, p. 277-279, 2014.

SANTOS, Karina T. et al. Agente comunitário de saúde: perfil adequado a realidade do Programa Saúde da Família. Ciência \& Saúde Coletiva, Rio de Janeiro, v. 16, supl. 1, p. 1.023-1.028, 2011.

SILVA, Nara H. L. P.; CARDOSO, Carmen L. Agentes comunitários de saúde: sentidos acerca do trabalho em HIV/Aids. Psicologia \& Sociedade, Belo Horizonte, v. 20, n. 2, p. 247-256, 2008.

WAISELFIZ, Julio J. Os novos padrões da violência homicida no Brasil. Mapa da violência,
2012. Disponível em: <http://www.mapadaviolencia.org.br/pdf2012/mapa2012_web.pdf>. Acesso em: 10 mar. 2018.

WOOD, Evan et al. Does this adult patient have early HIV infection? The Rational Clinical Examination Systematic Review. JAMA, Chicago, v. 312, n. 3, p. 278-285, 2014.

WHO (WORLD HEALTH ORGANIZATION). The Gap report - Unaids. Genebra: WHO, 2017. Disponível em: < http://www.who.int/topics/ hiv_aids/en/>. Acesso em: 10 de mar. 2018.

ZAMBENEDETTI, Gustavo; BOTH, Nalu. S. "A via que facilita é a mesma que dificulta": estigma e atenção em HIV-Aids na Estratégia Saúde da Família - ESF. Fractal, Revista de Psicologia, Niterói, v. 25, n. 1, p. 41-58, 2013.

ZAMBENEDETTI, Gustavo; SILVA, Rosane A. N. O paradoxo do território e os processos de estigmatização no acesso ao diagnóstico de HIV na Atenção Básica em Saúde. Estudos de Psicologia, Campinas, v. 20, n. 4, p. 229-240, 2015.

ZAMBENEDETTI, Gustavo; SILVA, Rosane A. N. Descentralização da atenção em HIV-Aids para a atenção básica: tensões e potencialidades. Physis: Revista de Saúde Coletiva, Rio de Janeiro, v. 26, n. 3, p. 785-806, 2016. 